\title{
Participation of Women in STEM Higher Education Programs in Latin America: The Issue of Inequality
}

\author{
Cristina Osorio, Vilma Viviana Ojeda-Caicedo, Jose Luis Villa and Sonia H. Contreras-Ortiz \\ Universidad Tecnológica de Bolívar, Colombia, cosorio@utb.edu.co, vojeda@utb.edu.co,jvilla@utb.edu.co, \\ scontreras@utb.edu.co
}

\begin{abstract}
The low participation of women in STEM fields has been considered a critical issue in our society. It affects the rights of women to receive high quality education, to develop their skills and to improve their career prospects. Additionally, it has a negative impact on the outcomes of science and engineering projects. This paper describes the methodology and preliminary results of the application of an instrument to measure indicators for gender equality in STEM programs. The SAGA survey, developed by UNESCO, was applied in fifteen European and Latin American universities within the framework of the W-STEM project. This paper presents the results of nine Latin American universities related to gender equality in student population and teaching staff, as well as attraction, access, and graduation of female vs male students. The gender gap is evident in all the indicators, so it is necessary to define policies and strategies to face this issue from different levels.

Keywords-Women in STEM, gender equality, Latin America.
\end{abstract}

\section{INTRODUCTION}

Women are $50 \%$ of the world's population, however, according to UNESCO Institute for Statistics (UIS), less than $30 \%$ of researchers are women. Globally, women are underrepresented in science, technology, engineering, and mathematics (STEM). Despite the progress that has been done to increase female student's enrollment rate in primary, secondary, and higher education, the gender gap in STEM fields persists, and gets worse as the level of education increases [1]. Currently, only $35 \%$ of STEM students are women [1]. Reducing this gap has become a priority in the world. STEM education plays a key role to achieve the 2030 Sustainable Development Goals (SDG). It is related to SDG 4, that refers to inclusive and equitable quality education, and SDG 5, that refers to gender equality and women empowerment. Gender parity can improve the quality of research and innovation, and contributes to creativity, productivity, and innovation in engineering projects $[1,2,3]$.

Girls and women deserve the same opportunities as boys and men to access STEM education and pursue STEM careers. In addition, engineering, and computing jobs offer a higher return of investment and better prospects than other jobs [3]. For example, in the US, the average wage for STEM jobs is almost twice the average wage for non-STEM jobs [4]. Due to the gender gap, women are missing valuable opportunities to get well paid jobs and improve the economic situation of their families and communities.

There are multiple causes of the gender gap in STEM: cultural stereotypes, lack of female role models, gender bias in hiring and promotion, gender bias in evaluation of scientific

Digital Object Identifier (DOI):

http://dx.doi.org/10.18687/LACCEI2020.1.1.368

ISBN: 978-958-52071-4-1 ISSN: 2414-6390 work, inadequate professional mentoring, hostile work environment, and familiar and caregiving responsibilities, among others [5]. Therefore, multiple interventions are needed to increase women participation in STEM [5].

Psychologists have reported that there is a "collective intelligence" that explains the performance of groups of people in a wide variety of tasks. The collective intelligence is more related to the social sensitivity of the group members and the proportion of females in the group, than to the average and maximum individual intelligence of the members [6]. Certainly, the development of Latin American countries can benefit from an increased participation of women in STEM.

In 2019, a consortium of fifteen universities started the W-STEM project: Building the future of Latin America, engaging women into STEM, funded by the European Union through the Erasmus + program. The main objective of the project is to improve the strategies and mechanisms of attraction, access, and guidance of women in Latin American STEM higher education programs [7]. Female students in STEM programs usually have feelings of isolation and intimidation, as they are outnumbered by their male peers $[5,8]$. Additionally, the lack of mathematical confidence, rather than the lack of mathematical ability, makes women 1.5 times more likely to drop out of school in the first semesters, according to a study conducted in the US [9]. For these reasons, the W-STEM project is focused not only on attraction and access, of women in STEM programs, it includes guidance, and retention of current students.

The development of the W-STEM project started with the design and application of an instrument for the institutions' self-assessment on gender equality in STEM. This paper presents the preliminary results of the self-assessment of nine Latin American higher education institutions from Colombia, Mexico, Costa Rica, Ecuador, and Chile.

\section{METHODOLOGY}

This paper shows a partial result of the W-STEM project [7]. In particular, we focus on the design and accomplishment of the self-assessment survey on gender equality in STEM.

The instrument for the self-assessment was based on the STEM and Gender Advancement (SAGA) survey by UNESCO [10]. According to the methodology proposed by the SAGA project, the approach to gender issues has two aspects:

1. Identification and design of indicators that allow identification, measurement and monitoring of drivers and barriers. 
2. Design evidence-based policies based on evidence and good practices.

The project focuses on three processes: attraction, access, and advising. For each process, a policy needs to be implemented to increase the participation of women in STEM. In order to define such policies, appropriate indicators should be designed to build a baseline, to assess and monitor progress and, if necessary, feedback on the policy.

\section{A. Identification and Design of Indicators}

The SAGA project proposes a policy survey implementation process with 8 steps [11]:

1. Build the framework

2. Assess available resources

3. Identify the target population

4. Adapt the survey

5. Select how to collect the information

6. Undertake a pilot

7. Conduct the survey

8. Review and validate results

Build the framework: the policy survey needs to ensure ownership by all relevant stakeholders ensuring a wide consultative process at the beginning of the implementation. In our case, this step was assured firstly presenting the project goals in the various instances of decision including academic and administrative councils, and supporting offices such as Planning, Students Welfare, Bureau of Personnel and Recruitment departments.

Assess available resources: one of the main resources for identifying indicators related to gender is the SAGA survey [10]. As stated in [7], the W-STEM project uses 25 indicators among the 45 indicators proposed by SAGA. These indicators are consistent with the aim of the project and congruous with the statistical information available in the participant universities.

Target Population. The target population of this project are young girls in high schools and female students of STEM undergraduate programs

Survey adaptation: a matrix of indicators was implemented in Excel, adapting the indicators to the particular case of the participating universities [7].

Information gathering: the survey was carried out by each one of the 15 universities participating in the W-STEM project in 2019 with data of 2018. No pilot was carried out in this opportunity.

Validation: the results were validated with internal reviews in each university and during the W-STEM
International Leadership Summit in Barranquilla and Cartagena (Colombia) in November 2019.

Similarly, SAGA proposes a Drivers and Barriers survey implementation process with 8 steps [12]:

1. Define objectives and research questions (review of existing literature)

2. Identify the survey population

3. Adapt the survey questionnaire

4. Select how to collect the information

5. Test the survey

6. Conduct the survey

7. Process the information collected

8. Review and validate the results and data quality

In order to ensure the usefulness of the results to reach the goals, it is required to specify and clearly enunciate the objectives and research questions in as much detail as possible.

\section{B. Evidence-based Policy Design}

In a second step of this project, an evidence-based policy design should be performed. To address this stage, an action plan was designed with the aim of enhancing the performance of each university regarding the indicators used in the precedent subsection. These action plans should be validated, and the results of such plans will be published later.

\section{RESULTS}

The instrument based on the SAGA survey was used to collect data on gender equality in student population, staff, attraction, access, and graduation in the institutions that participate in the project. In this section, we present the data compiled in nine Latin American Universities:

1. Universidad del Norte (UNINORTE) - Colombia

2. Universidad Tecnológica de Bolívar (UTB) Colombia

3. Tecnológico de Monterrey (ITESM) - México

4. Universidad de Guadalajara (UDG) - México

5. Universidad de Costa Rica (UCR) - Costa Rica

6. Instituto Tecnológico de Costa Rica (ITCR) - Costa Rica

7. Universidad Técnica del Norte (UTN) - Ecuador

8. Universidad Técnica Particular de Loja (UTPL) Ecuador

9. Pontificia Universidad Católica de Valparaíso (PUCV) - Chile 


\section{A. Gender Equality in Student Population}

Fig. 1 shows the total number of male and female students of these institutions, in science and engineering programs. We can observe that the gender gap is evident in engineering programs, and not in science programs for these institutions. Female students are only $27.8 \%$ of the total student population in engineering programs. Fig. 2 shows the percentages of male and female students in STEM programs per country. The gender gap is very similar across the countries.

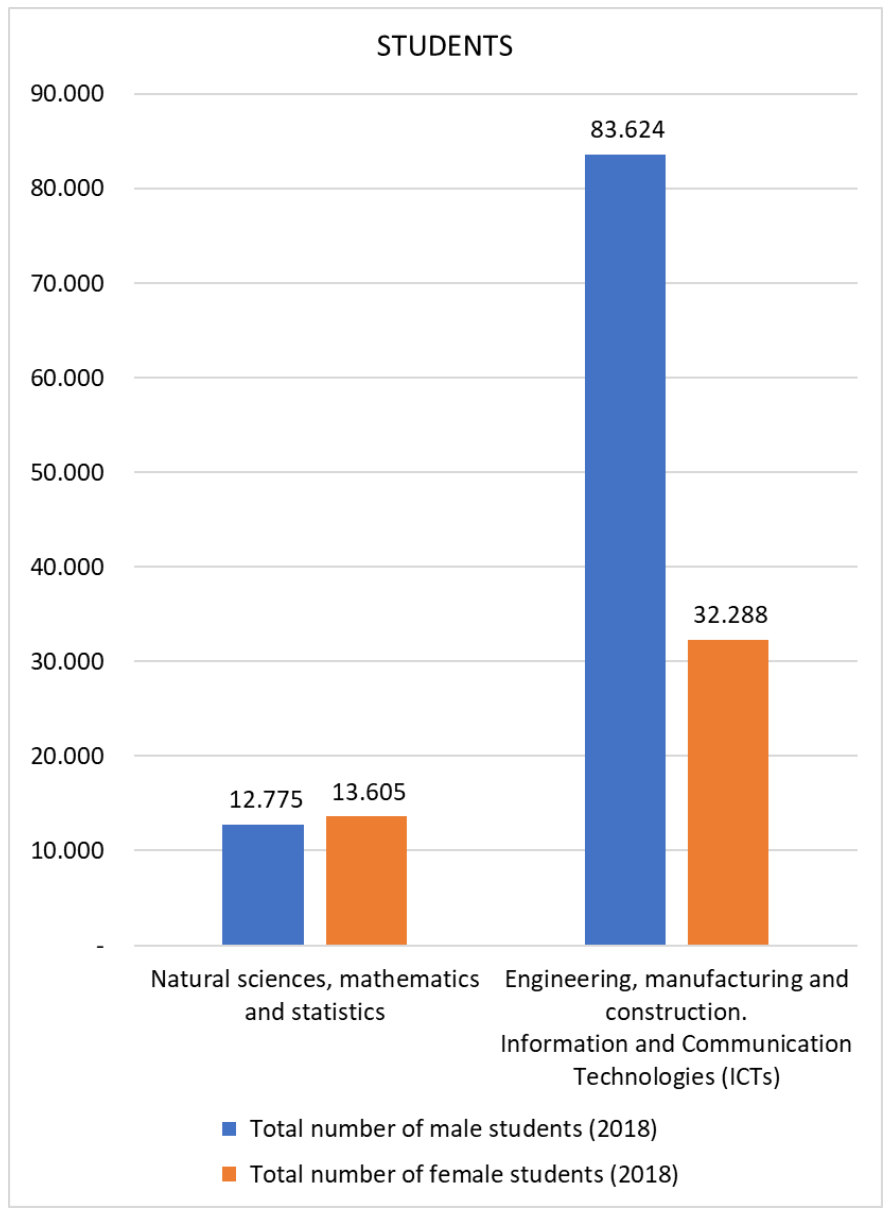

Fig. 1 Student population in science and engineering programs by gender in nine Latin American universities.

\section{B. Gender Equality in Teaching Staff}

Figs. 3 and 4 show the total number of teaching staff by gender in STEM programs of the nine Latin American universities considered. Female professors account for only $25.9 \%$ of the total number of professors in science programs, and $40.9 \%$ in engineering programs in these universities.

\section{Attraction, Access, and Graduation by Gender}

The data in this section are from six institutions: UTB, UNINORTE, UCR, ITCR, UTPL and PUCV. The information from the other three institutions (ITESM, UDG and UTN) was not complete when this paper was written. Figs. 5 and 6 show the number of applicants, admitted applicants, enrolled undergraduate students and graduates from science and engineering programs respectively in 2018. Fig. 7 shows the total number of applicants, admitted applicants, enrolled students, and graduates from all STEM programs of the six universities in 2018.

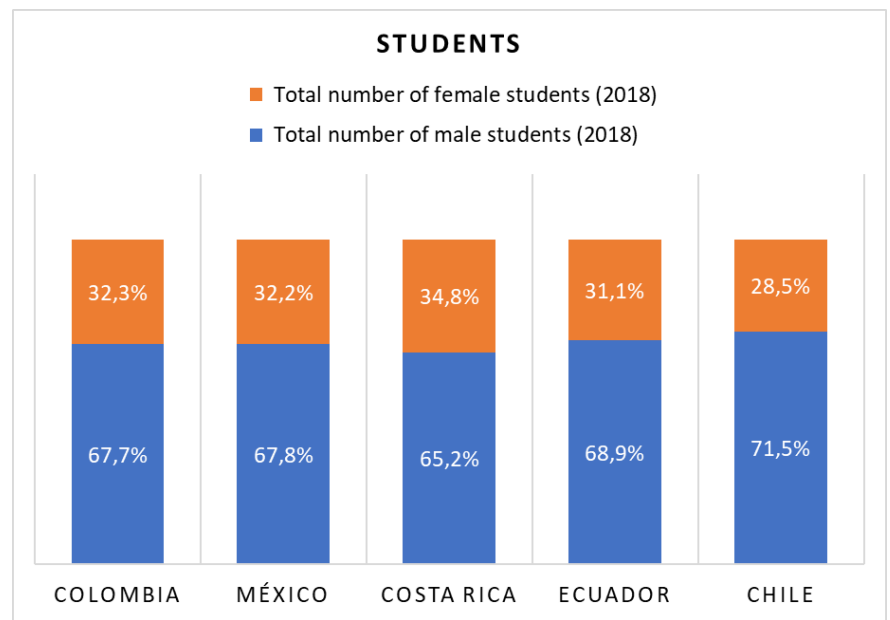

Fig. 2 Student population in STEM programs by gender in the participant institutions from five Latin American countries.

\section{Staff members - Natural sciences, mathematics and statistics}

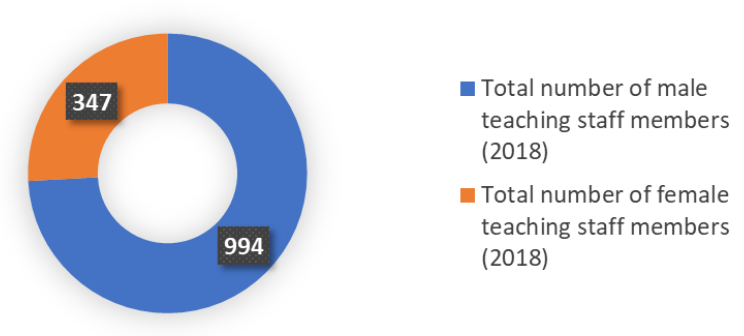

Fig. 3 Teaching staff in science programs by gender in nine Latin American universities.

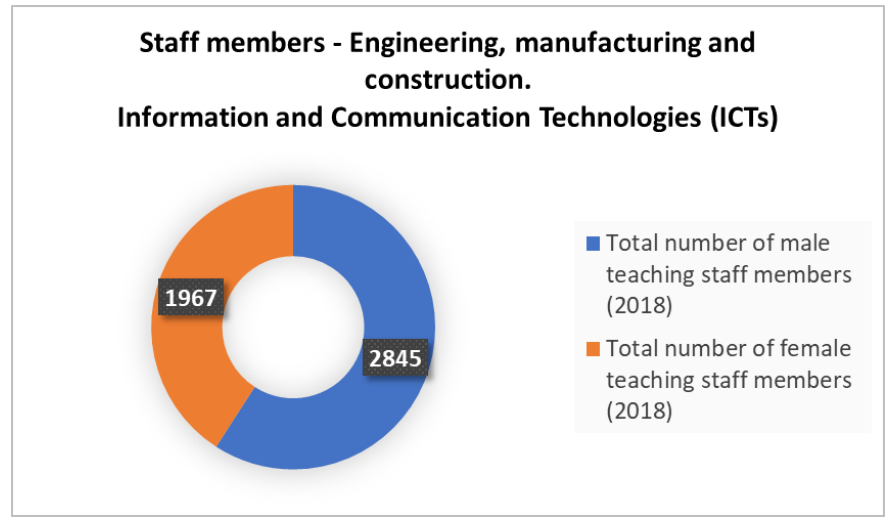

Fig. 4 Teaching staff in engineering programs by gender in nine Latin American universities. 


\section{DISCUSSION}

The results of this study show that the reduced number of female students in STEM programs is also observed in the case of female teaching staff. The gender gap is wider in science faculty vs engineering faculty. Female professors are $25.9 \%$ of the total number of professors in science programs, and $40.9 \%$ of professors in engineering programs. This fact limits the access of female students to female role models and mentors. Previous studies have shown that female students taking math courses with female professors (compared to male professors) felt more confident about their math skills [5].

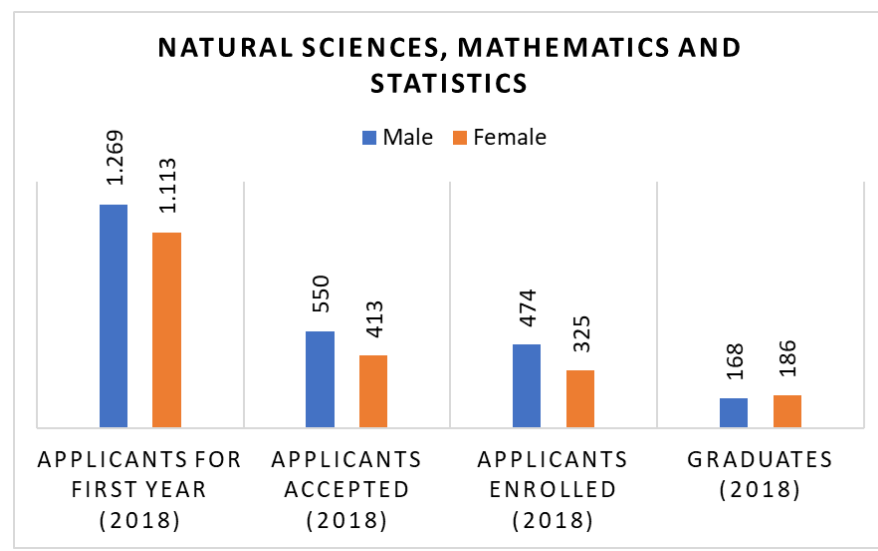

Fig. 5 Number of applicants, admitted applicants, enrolled students, and graduates in science programs of six Latin American universities.

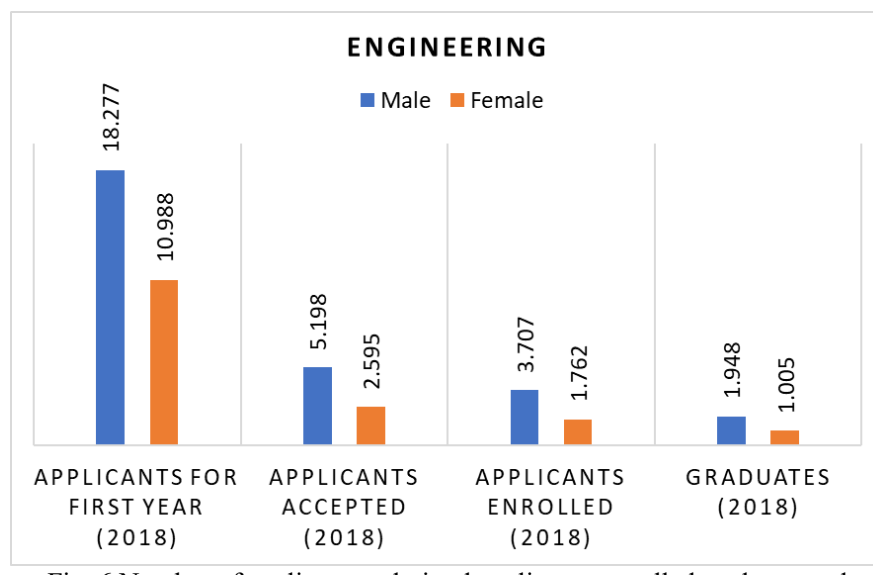

Fig. 6 Number of applicants, admitted applicants, enrolled students, and graduates in engineering programs of six Latin American universities.

In 2018, 12101 women applied to STEM programs vs 19546 men in six universities (UTB, UNINORTE, UCR, ITCR, UTPL and PUCV). Therefore, women were $38.4 \%$ of the applicants. The gender gap is higher in engineering programs compared to science programs. With respect to the absorption rate, defined as the ratio of students enrolled in the first semester of a program to the number of applicants, it is $21.4 \%$ for men vs $17.2 \%$ for women. This means that the access to STEM programs is lower for women than for men, which worsens the gender gap. With respect to graduates, in
2018 there was gender parity in science programs, but in engineering programs, only $34 \%$ of graduates were women.

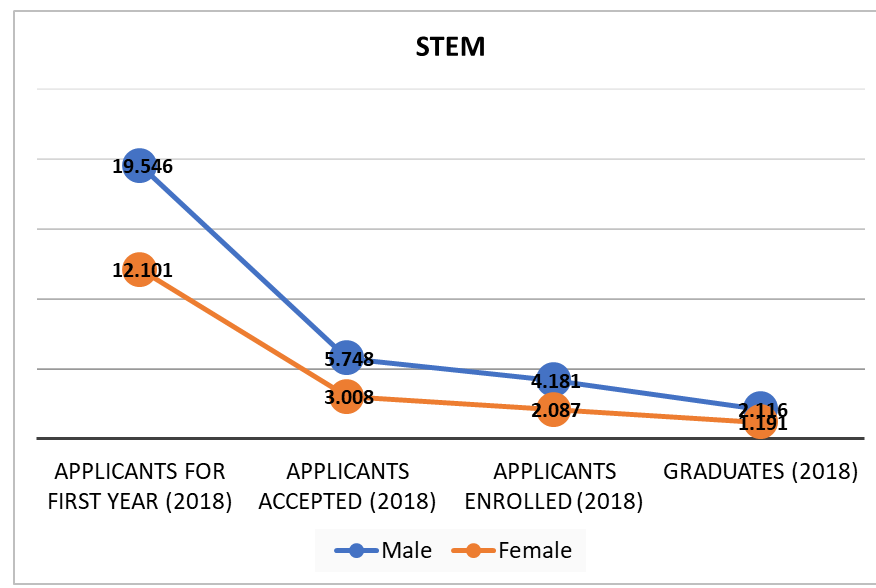

Fig. 7 Number of applicants, admitted applicants, enrolled students, and graduates in STEM programs of six Latin American universities.

These results evidence gender inequality in students, teaching staff, attraction, access, and graduation of STEM programs of the participant Latin American universities. To reduce the gender gap in STEM fields, the W-STEM project has defined the following strategies:

1. Measuring gender equality in enrolment and retention rates in STEM programs. As described in this paper, the universities were provided with an instrument to measure different indicators of gender equality. It is important that the institutions implement strategies to collect, organize, analyze, and monitor that information.

2. Implementing policies, strategies and organizational mechanisms for improving attraction, access, and guidance of women in STEM programs. The leaders of academic institutions should be aware of the gender gap in STEM fields and commit to developing mechanisms to reduce it. Some examples of these strategies are gender equality offices to provide advice and information on gender issues, child care facilities for staff and students with young children, counseling for drop-out prevention, and protocols for harassment and discrimination.

3. Promoting STEM studies vocation and choice in girls and young women in secondary schools as well as guidance in the first year of the STEM program. The universities are developing attraction and sensibilization campaigns targeted at female high school students. These campaigns include activities such as webinars, workshops, short courses in topics like robotics and programming, student groups, and talks with women in STEM. Another strategy that can be mentioned is the program \#MujerUTB. This program highlights female role models in science and engineering through forums with women in STEM developed in three phases of the pedagogical process: remembrance or evocation of experience; reflexive criticism and analysis or social transformation. Additionally, short courses in programming and citizen 
science [13] have been offered to elementary school girls to promote STEM fields.

4. Developing online tools to implement effective strategies to enhance attraction, access, retention, and guidance of women in STEM programs. A mobile application is being developed to promote STEM fields in young women. The application will include more than 1500 profiles of engineering and science students and graduates from the fifteen universities of the project, and videos of women in STEM telling their life experience.

\section{CONCLUSIONS AND FUTURE WORK}

The results of this study suggest that it is necessary to develop and strengthen gender equality mechanisms to improve indicators of attraction, access, guidance, and graduation of female students in Latin American STEM programs. Gender inequality is more pronounced in the student population of engineering programs, and teaching staff of science programs. Therefore, Latin American higher education institutions should continue developing strategies to achieve gender equality, especially in programs with wider gender gaps, and these strategies should be supported by institutional policies.

After the implementation of the strategies and mechanisms of attraction, access, retention, and guidance of women in STEM programs, the institutions in the W-STEM project will measure their impact by comparing indicators at the initial, mid, and final terms. These indicators include women enrollment rates, inclusion or adaptation of policies and strategies, and guidance initiatives.

\section{ACKNOWLEDGMENT}

The authors thank European Union through the Erasmus+ Programme in its Key Action 2 "Capacity-building in Higher Education" for supporting the W-STEM project (Ref. 598923EPP-1-2018-1-ES-EPPKA2-CBHE-JP); and UNESCO and COLUMBUS for their valuable advice in the development of the activities of the project.

\section{REFERENCES}

[1] Chavatzia, Theophania. Cracking the code: Girls' and women's education in science, technology, engineering and mathematics (STEM). Vol. 253479. Paris: UNESCO Retrieved from http://unesdoc. unesco. org/images/0025/002534, 2017.

[2] Lee, Heisook, and Elizabeth Pollitzer. Gender in science and innovation as component of inclusive socioeconomic growth. Portia Limited, 2016.

[3] Corbett, Christianne, and Catherine Hill. Solving the Equation: The Variables for Women's Success in Engineering and Computing. American Association of University Women. 1111 Sixteenth Street NW, Washington, DC 20036, 2015.

[4] Fayer, Stella, Alan Lacey, and Audrey Watson. "STEM occupations: Past, present, and future." Spotlight on Statistics (2017): 1-35.

[5] Dasgupta, Nilanjana, and Jane G. Stout. "Girls and women in science, technology, engineering, and mathematics: STEMing the tide and broadening participation in STEM careers." Policy Insights from the Behavioral and Brain Sciences 1, no. 1 (2014): 21-29.
[6] Woolley, Anita Williams, Christopher F. Chabris, Alex Pentland, Nada Hashmi, and Thomas W. Malone. "Evidence for a collective intelligence factor in the performance of human groups." science 330, no. 6004 (2010): 686-688.

[7] García-Holgado, Alicia, Amparo Camacho Díaz, and Francisco J. GarcíaPeñalvo. "Engaging women into STEM in Latin America: W-STEM project." In Proceedings of the Seventh International Conference on Technological Ecosystems for Enhancing Multiculturality, pp. 232-239. ACM, 2019.

[8] Clark Blickenstaff*, Jacob. "Women and science careers: leaky pipeline or gender filter?." Gender and education 17, no. 4 (2005): 369-386.

[9] Ellis, Jessica, Bailey K. Fosdick, and Chris Rasmussen. "Women 1.5 times more likely to leave STEM pipeline after calculus compared to men: Lack of mathematical confidence a potential culprit." PloS one 11, no. 7 (2016): e0157447.

[10]UNESCO, Measuring Gender Equality in Science and Engineering: the SAGA Toolkit, SAGA Working Paper 2, Paris, 2017.

[11]UNESCO, the SAGA Survey of Gender Equality STI Policies and Instruments, SAGA Working Paper 3, Paris, 2018.

[12]UNESCO, The SAGA Survey of Drivers and Barriers to Careers in Science and Engineering, SAGA Working Paper 4, Paris, 2018.

[13]Finquelievich, Susana, and Celina Fischnaller. "Ciencia ciudadana en la Sociedad de la Información: nuevas tendencias a nivel mundial." Revista Iberoamericana CTS, no. 27, vol. 9 (2014): 11-31. 